\title{
Analysis on Social Media Addiction using Data Mining Technique
}

\author{
D. Radha \\ M.O.P Vaishnav College for \\ Women(Autonomous), \\ Chennai
}

\author{
R. Jayaparvathy \\ SSN College of engineering, \\ Chennai
}

\author{
D. Yamini \\ M.O.P Vaishnav College for \\ Women(Autonomous), \\ Chennai
}

\begin{abstract}
The popularity of social media applications has changed the way of communication for the past few years. The transfer of information from one individual to another had grown beyond the basic act of texting and evolved to enable the transfer of other media such as image, audio, video. An example of such an application is WhatsApp. WhatsApp is a popular application which is used widely for texting, calling, transferring media. This paper attempts to classify the behavioral aspects of a user to predict if they are addicted or not. The positive impacts of using a smart phone application on online businesses and how WhatsApp has become a trendsetter among the youngsters of the current generation and the increasing frequency of its users among college students have been discussed by prior works. The objective of this paper is to predict whether a particular individual is said to be addicted to WhatsApp or not. The conclusion is expected to expose the level of addiction to WhatsApp. It is expected to be high assuming the increasing density of users. Data mining is the practice of examining large pre-existing databases in order to generate new information.
\end{abstract}

\section{General Terms}

Your general terms must be any term which can be used for general classification of the submitted material such as Pattern Recognition, Security, Algorithms et. al.

\section{Keywords}

WhatsApp, Psychology, User behavior, Technological improvements, Communication, Response level, Usage of app, Data mining

\section{INTRODUCTION}

In current scenario, the usage of WhatsApp has accelerated due to various factors such as ease of use, essential features. WhatsApp was founded in 2009 by Brian Action and Jon Koum. In June 2009 WhatsApp was updated so that each time the user changed their status, it would alert everyone in the user's contacts. By Feb 2013, WhatsApp's user base had increased to about 210 million active users. The users have the ability to interact with others through texting, calling, and transferring media. The classification of users as those addicted and not addicted and thus predicting the level of addiction is the aim of this paper.

Data mining is the process of analyzing data from a wide perspective and summarizing it into useful information performed through tasks like clustering, classification, associative relative method and so on. Through the process of classification, the attributes that might lead to this addiction is established.
Classification is a data mining technique used to predict collective standard for the data instances. Classification is said to be done by two methods. Supervised classification, where the set of possible data is known beforehand and unsupervised classification, where the set of data are not known in advance. A decision tree is a structure commonly used in classification that indicates the possible outcome of a model using the technique of data mining. Classification is used to indicate the probability to act in a certain way or the similarity to objects that are part of a particular class.

\section{LITERARTURE REVIEW}

\subsection{Positive impact of smartphone applications: WhatsApp \& Facebook for Online business}

This paper by Jamaluddin Ibrahim, Rafidah Chee Ros, Nurul Faatihah Sulaiman, Roszaini Che Nordin \& Li Ze studied the positive impacts of using smartphone applications for online business processes. Their analysis found that exposing the newer technologies can help to develop business success and benefit people.

\subsection{Customer satisfaction towards WhatsApp}

This paper by Khyati M Patel studied the customers satisfaction of using WhatsApp to purchase products. Her analysis found that managers of any sector, must be intelligent about each and every aspect of marketing their products using WhatsApp.

\subsection{WhatsApp: A Trend Setter in Mobile \\ Communication among Chennai Youth}

This paper by Ms. Jisha K and Dr. Jebakumar studied the relation between WhatsApp and the current trends in mobile communication among the youngsters in Chennai. Their analysis revealed that smart devices are making the present generation the most connected.

\subsection{The Adoption of WhatsApp: Breaking the Vicious Cycle of Technological Poverty in South Africa}

This paper by Richard Shambare Tshwane studied the use of WhatsApp to overcome the situation of technological poverty in South Africa. His analysis found that a combination of cost efficiency, simple and user-friendly features, influences the users to adopt WhatsApp. 


\section{SYSTEM MODEL}

The data used here comprises of certain characteristics that define how much a particular person is using WhatsApp, such as the years of usage, duration of usage in a day, the response levels, for what purpose WhatsApp is being used, what alternate application is used and how often. The main attributes set for this analysis is how long were they using WhatsApp, duration of use per day and how often do they reply i.e., the response rate.

\section{PERFORMANCE AND ANALYSIS}

The value for the result attribute is predicted according to the assumption that if a person uses WhatsApp more than 5 hours continuously, he/she is addicted. The tool, RapidMiner is used develop a decision tree(As shown in Figure 1) for the collected data.

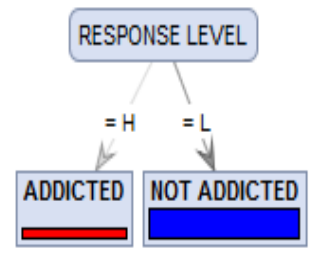

Figure 1

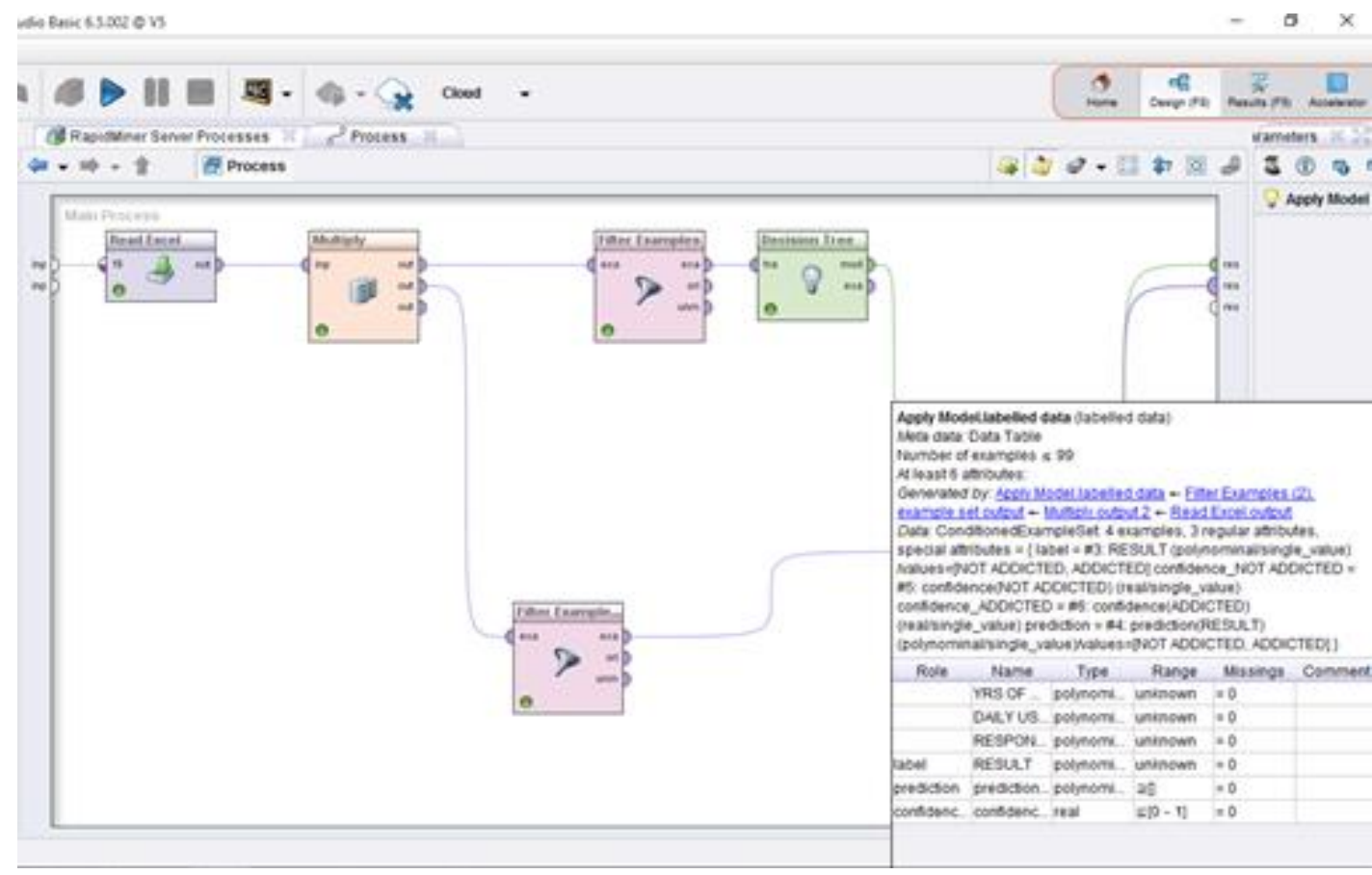

Figure 2

It is assumed that if a person is using WhatsApp for more than 4 years and more than 5 hours a day, the individual is addicted. RapidMiner, a tool used for mining the data is deployed and the result attribute is kept as the label attribute.

This model is applied to the data using the RapidMiner tool, with the idea of predicting whether the person is addicted or not(As shown in Figure 2).
Here certain values are found to be missing in the label attribute. (As shown in Figure 3)

RapidMiner tool is used to predict the value of label attributes for new entries. 


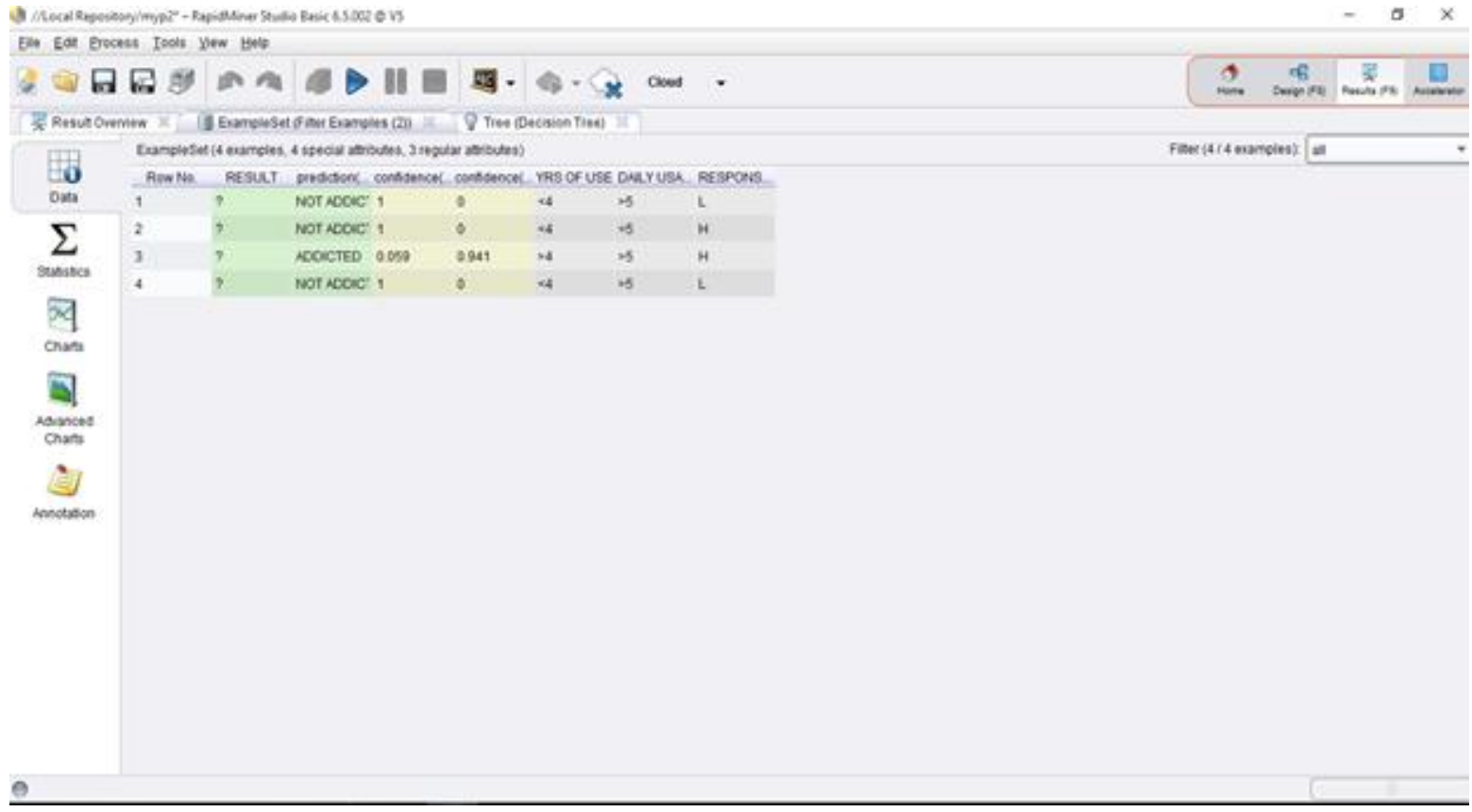

Figure 3

Identification of whether an individual is addicted or not is done.
The accuracy of this model is also validated using the $\mathrm{x}$ validation operator(As shown in Figure 4) and was found to be about 90\%. (As shown in Figure 5)

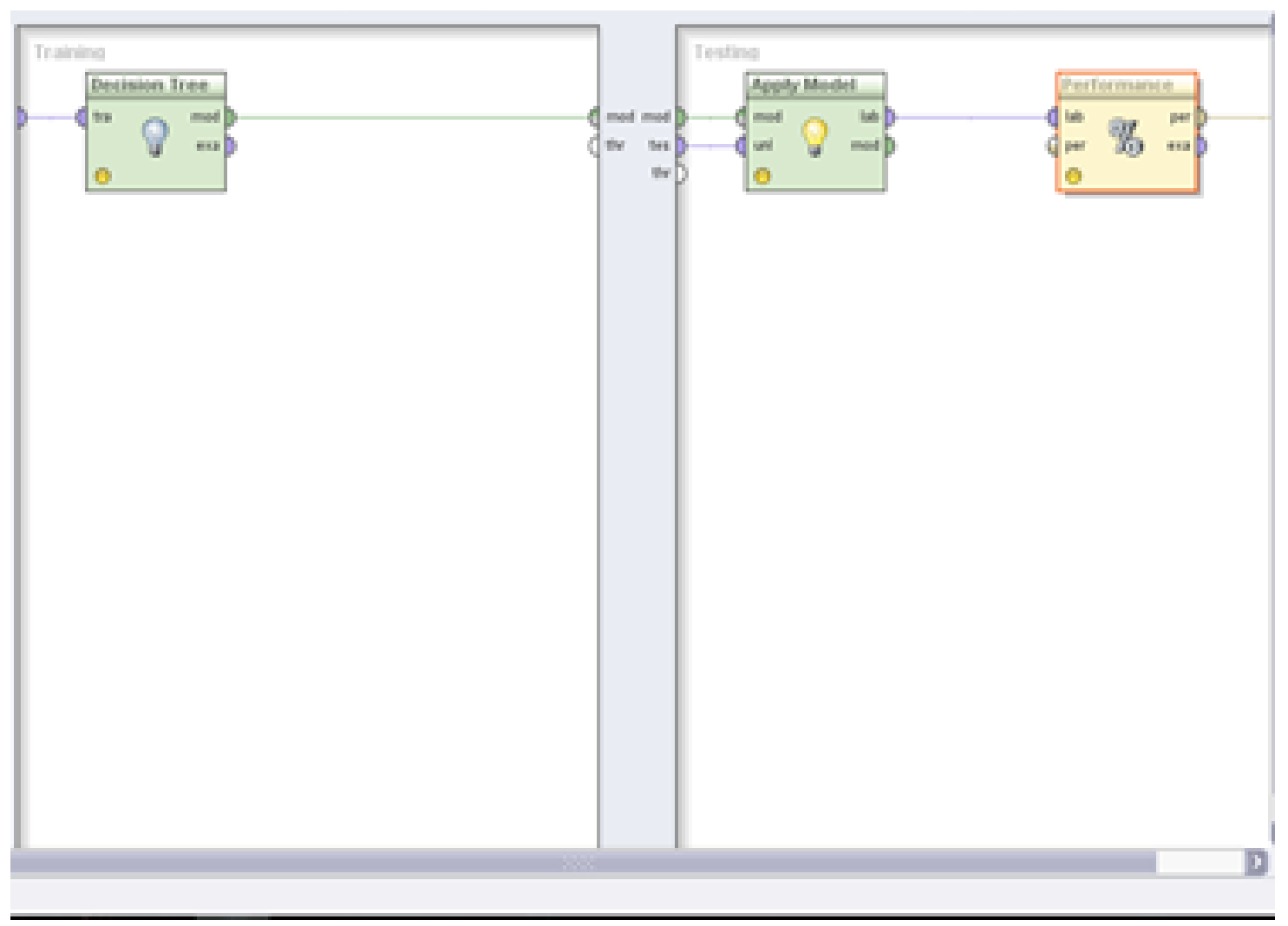

Figure 4 


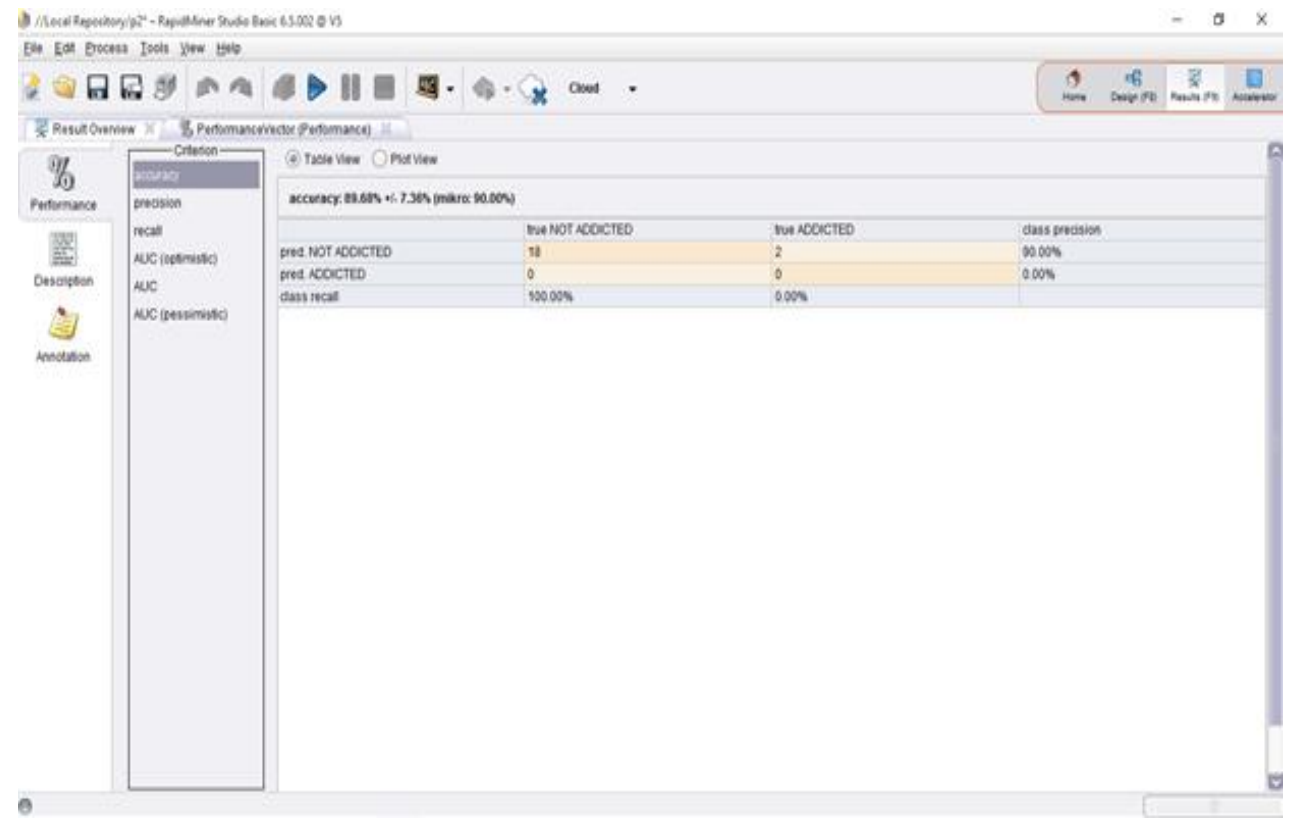

Figure 5

\section{CONCLUSION}

From this analysis, it is found that a majority of the users are addicted to WhatsApp. Also the features of WhatsApp, like calling, transfer of contacts and locations, easy user interface and its platform independence has found to be responsible for this increase in use. Thus the analysis exposes the positive impacts and the negative impacts of this application that might lead to addiction. Further analysis will be done to find the segment of population like women, men, college students, business officials that is most addicted to WhatsApp.

\section{REFERENCES}

[1] Jamaluddin Ibrahim, Rafidah Chee Ros, Nurul Faatihah Sulaiman, Roszaini Che Nordin,\& Li Ze, "Positive impact of smartphone applications: WhatsApp \& Facebook for Online business", IJSRP

[2] Khyati M Patel ,"Customer satisfaction towards WhatsApp" , Golden Jubilee Institute of Business Administration

[3] Dr. P. Uma Maheswari , "Frequency of using WhatsApp Messenger among college students in Salem district, TamilNadu", IJCSMA
[4] Ms. Jisha K , Dr. Jebakumar ,'WhatsApp: A Trend Setter in Mobile Communication among Chennai Youth", IOSR

[5] Richard Shambare Tshwane, "The Adoption of WhatsApp: Breaking the Vicious Cycle of Technological Poverty in South Africa", Journal of Economics and Behavioral Studies

[6] Dan Bouhnik , Mor Deshen, "WhatsApp goes to school:Mobile Instant Messaging between teachers and students", JITE

[7] Johnson Yeboah,Geoge Dominic, "The Impact of WhatsApp messenger usage on students performance in tertiary institutions in Ghana",Journal of Education and Practice

[8] Neelamadhab Padhay,Dr. Pragnyaban Mishra,Rasmita Panigrahi, "The survey of data mining applications and features", IJCSEIT

[9] Nitin Agarwal, Ehtesham Haque,Huan Liu,Lance Parsons, "Research paper recommender systems: A subspace clustering approach", IAC

[10] Arpit Gupta,Ankit Gupta,Amit Mishra, "Research paper on cluster techniques of data variations", IJATER 